\title{
Pensar los territorios del desarrollo: sustentabilidad y acción pública en nombre de una ciudad imaginaria. Concepción (Chile), 1950-2010
}

Enrique Aliste. Universidad de Chile, Santiago, Chile.

Alain Musset. École des Hautes Études en Sciences Sociales, París, Francia.

RESUMEN | La discusión sobre el desarrollo pensado desde la noción de territorio se plantea acá como desafío central. Así, se exploran elementos que van otorgándole paulatinamente sustento a la noción de ciudad, sobre la base de los diferentes discursos del desarrollo hoy vigentes. Desde esta idea, se intenta problematizar la concepción de territorio en el ámbito de la acción pública, y se indaga en la forma en que, desde las prácticas discursivas, se articulan las prácticas espaciales que crean nuevas formas de organización y valoración espacial. Se concluye, para abrir una discusión más a largo plazo, que mirar la ciudad como objeto de planificación parece poco acertado, en tanto esta es más un proceso y una dinámica permanente que un ente estático, el cual geo-históricamente muestra tendencias y formas que adquieren sentido en el tiempo; y que, por lo mismo, se vuelve necesario mirar la ciudad en una perspectiva más amplia. Lo anterior se explora y analiza en el caso del Área Metropolitana de Concepción (AMC).

PALABRAS CLAVE | desarrollo sustentable, geografía social, imaginarios urbanos.

ABSTRACT | The discussion of a development plan conceived from the notion of territory is proposed here as a central challenge. Thus, items that are gradually giving support to the notion of the city, on the basis of the different discourses about development prevalent today. From this starting point, we try to problematize the concept of territory in the field of public action, and explore how new forms of organization and spatial assessments are articulated stemming from discourse practices. We conclude, opening a longer-term discussion, that to look at the city as an object of planning seems unwise, as it is more a dynamic process than a static entity. Geo-historically it evidences trends and forms that only make sense in time, making it necessary to look at the city in a broader perspective. This is explored and discussed in the case of Metropolitan Area of Concepcion (AMC).

KEY WORDS | sustainable development, social geography, urban imageries.

Recibido el 1 de marzo de 2012, aprobado el 19 de marzo de 2013

E-mail: Enrique Aliste, ealiste@uchilefau.cl | Alain Musset, alain.musset@ehess.fr

Artículo elaborado en el marco de la Cooperación Internacional del Proyecto FONDECYT 1090248 "Huellas y dinámicas territoriales: imaginarios del desarrollo y prácticas de transformación del ambiente en el Gran Concepción”. 


\section{Introducción}

Hay una tensión entre una ciudad real-que es una ciudad negada, negativa, una ciudad invadida, un oximoron: es una ciudad bárbara-y la que se le contrapone: una ciudad imaginaria, futura, ausente, que en verdad es una ciudad extranjera.

(Ricardo Piglia, La ciudad ausente)

Pensar el ordenamiento y gestión de los territorios en el campo de la planificación, es algo que puede hacerse desde diversas perspectivas y entradas; hacerlo desde la noción de desarrollo como práctica discursiva es una más de ellas, y su propósito es explorar los elementos que inciden y repercuten en la idea de ciudad y en sus aspectos tanto materiales como imaginarios.

La idea misma de planificación, alcances y modo de ejercerla, al amparo de ciertos elementos discursivos, se pone en tensión cuando el prisma de observación es el largo plazo, en una perspectiva orientada a determinar el papel que efectivamente ocupa el territorio en los discursos sobre el desarrollo ${ }^{1}$. Desde este enfoque, la noción de desarrollo como motor articulador de procesos y transformaciones territoriales, vigente en discursos de diverso tipo, va moldeando un territorio ausente en cierto modo, y presente en otro. Va cruzando criterios, alcances y formas que quedan en evidencia en las llamadas "huellas territoriales", esto es, las marcas que, como signos de ciertos momentos, permiten comprender el trazo del tiempo en el espacio (Braudel, 1997). Tal como señala Schlögel (2007), “¿Qué ganamos en percepción y perspicacia histórica si nos tomamos en serio por fin (de nuevo) espacios y lugares?” (p. 15).

Pero no se trata de una mirada solo a las ideas. Es también y, por sobre todo, una mirada a las evidencias y rezagos que el espacio muestra como testimonios de la acción del tiempo sobre él (Braudel, 1997). Y por cierto, un intento de comprender este espacio cuyos atributos de diverso orden -sean económicos, ecológicos, sociales, culturales o políticos- van otorgándole el sentido que hará posible, en definitiva, hablar con propiedad de territorios (Di Méo, 1998).

Este texto busca por sobre todo exponer una reflexión sobre datos, antecedentes y hallazgos, discutidos desde un plano conjetural. Se trata de un estudio cimentado en una perspectiva más bien cualitativa e interpretativa, cuyo sentido es, así, sobre todo hermenéutico. Más que construir juicios certeros o conclusiones definitivas, tiene la ambiciosa pretensión de comenzar a articular un debate sobre el modo en que miramos, entendemos y buscamos actuar en el ámbito de la planificación y ordenación territorial. Se sitúa, por tanto, en una perspectiva considerada corrientemente como básica y preliminar: observar e intentar

La idea de "larga duración" (long durée) de Fernand Braudel, si bien se usa acá, se hace con cautela, en tanto que la mirada de larga duración en los procesos que atañen a la noción de desarrollo no va más allá del siglo xx, y tiende a ser más evidente a partir de su segunda mitad. De esta forma, la mirada de larga duración que busca la comprensión geohistórica desde procesos que pueden abarcar muchos siglos (Braudel, 1997), se contextualiza en este caso mirando el proceso de una ciudad transformada a partir de los grandes cambios del siglo xx y tensionada permanentemente por acontecimientos catastróficos de origen natural. 
comprender. A manera de un ejercicio, entonces, el artículo quiere proponer un modo de observación y, desde aquí, previo a ofrecer alternativas concluyentes, avanzar un juicio discutido en perspectiva.

Hablar de ciudad imaginaria apunta básicamente a las diferentes formas y maneras en que ella ha sido concebida en el transcurso del tiempo, frente a las prácticas espaciales que van en paralelo ${ }^{2}$ (Chesneau \& Roncayolo, 2011), otorgándole significado en tanto manera concreta de articular y crear formas de organización espacial. Por ello, confrontar estas dos dinámicas -la creación y la articulación de formas de organización espacial- en un contexto que ofrezca razones o motivaciones de orden político, económico, cultural, social o natural, es parte de lo que se busca: abrir una discusión para el reencuentro con las distintas posibilidades y maneras de describir, caracterizar -comprender, en definitiva- la noción de ciudad, de territorio y de espacio desde el plano de los discursos, que en el presente caso es el del desarrollo.

\section{Una dinámica particular: la telúrica ciudad de las aguas amenazantes}

El Área Metropolitana de Concepción (AMC) cuenta en su historia con un sinnúmero de eventos catastróficos de diversa consideración. La tierra no parece del todo amigable en esta zona y el acto de habitar parece estar consignado en todo momento como un verdadero desafío. Es lo sucedido en la seguidilla de terremotos, maremotos e inundaciones (Pacheco, 1997; Musset, 2010) que cada década dejan su huella, para plasmar en la memoria de la ciudad un extraño sentimiento respecto de la indomabilidad de una naturaleza hostil con la cual se debe convivir a diario. Ello colabora en ir plasmando en este territorio una particular geografía que es rica no solo en elementos para su estudio físico-natural; lo es también, y por la misma razón, para su enfoque desde una perspectiva cultural, que colabore en aproximarse a aquella geografía social que busca ser leída en perspectiva (Di Méo \& Buléon, 2005). Esta dimensión va dejando una huella indeleble pero poco visible de sensaciones y de una sensibilidad poco explorada en general: allí, los imaginarios también consiguen situar y dar a la ciudad una morfología difusa, pero que desempeña un papel en las formas de entenderla y vivirla (Frémont, 1995). El riesgo, el miedo, la rudeza, la valentía o el desafío serán atributos que también espacialmente tendrán una función en esta construcción social del territorio.

Diversos testimonios dan cuenta de esta situación desde un punto de vista físico natural. Difícil es precisar cada uno de los riquísimos e indispensables estudios

2 Tal como lo señalan Chesneau y Roncayolo (2011), "lo imaginario no es una evasión fuera de lo real, sino más bien otra forma de establecer una relación con la realidad”, citando a Sansot. Efectivamente, Roncayolo se pregunta cuál es el papel que ocupa esta dimensión imaginaria en el contexto de la vida urbana, en tanto constancia presente en nuestras representaciones y prácticas cotidianas. Para Roncayolo, lo imaginario corresponde a la construcción de un escenario en donde la fuerza reside en una relación abierta a lo real, en tanto imaginario e imaginación, ambos términos provenientes de un tronco etimológico común relacionado con la idea de imagen; así, lo imaginario se reproduce y se encuentra tanto en representaciones (mentales y materiales) como en la memoria, y por ello tiene un fuerte anclaje en lo real. Tal como lo seńala el autor, lo imaginario establece, por una parte, un fuerte vínculo con lo real, pero, al mismo tiempo, es capaz de sobrepasar dicha realidad, y suele hacerlo (Chesneau \& Roncayolo, 2011, pp. 203-204). 
realizados en la zona, pero por señalar solo algunos de los argumentos que han permitido un avance en la comprensión de su compleja estructura geomorfológica, a lo que se apunta en general es a identificar las dificultades que físicamente ofrece este terreno a su poblamiento (Mardones \& Vidal, 2001; Ilabaca, 1995, 1993). Las complejidades geomorfológicas, miradas sistémicamente, permiten comprender, y al mismo tiempo avanzar en la valoración de la riqueza que tiene la zona en términos ecosistémicos y en cuanto a sus servicios ambientales. Es precisamente por tal conjunción que algunas de las acciones desarrolladas en términos de intervenciones urbanas son entendidas como profundamente impactantes desde el punto de vista ambiental (Smith \& Romero, 2009), con lo que comprometen la sustentabilidad urbana (Rojas, Muniz \& García, 2009).

Hay dos elementos de relevancia fundamental que, en el caso del Área Metropolitana de Concepción, inciden de una u otra forma en la idea de ciudad: la tierra y el agua. Lo telúrico y lo hídrico, así como le otorgan su sello, también generan aquella tensión que otorga sentido difuso a un proyecto de desarrollo fallido y esquivo.

La pregunta, entonces, que parece simple, pero no resulta evidente de responder, es cómo se mira e incluye esta mirada de elementos tan básicamente significativos para la ciudad. La antigua y presocrática Grecia entendía que los elementos tierra, agua, aire y fuego eran cruciales en la comprensión del mundo. La quintaescencia o el éter, sugeridos por Aristóteles y retomados por los científicos del siglo XIX, permitieron avanzar en la idea de que algo impregnaba la posibilidad de articulación entre dichos elementos. Hoy podríamos especular que la quintaesencia que permite articular los elementos para conseguir el anhelado progreso humano es el concepto de desarrollo.

El devenir territorial de Concepción, desde su fundación en 1550, ha estado de una u otra forma sujeto a la acción telúrica. Hito esencial en este sentido es el traslado de la ciudad desde el sitio de Penco a su actual emplazamiento en el valle de La Mocha, luego del catastrófico terremoto y maremoto de 1751 (Hernández, 1983; Mazzei \& Pacheco, 1985; Musset, 2010).

Desde entonces, diversos procesos de ocupación han ido poniendo a la ciudad en una tensión permanente con las aguas. Las inundaciones que cada invierno son comunes, y que en algunos años han alcanzado dimensiones catastróficas (1899, 1951, 1965 y 2006, por ejemplo), no debieran ser motivo de gran sorpresa a la luz de las condiciones de emplazamiento de la ciudad en terrenos que geomorfológicamente corresponden a marismas y humedales (Ilabaca, 1993). Mardones y Vidal (2001) identifican más de 38 inundaciones relevantes entre 1960 y 1990. Ya en el "Plano de la Bahía de Concepción" de A. Coste, en 1790 (Figura 1), se representaban las condiciones de humedal y marismas en la actual zona de emplazamiento urbano del AMC.

Pero también es cierto que las condiciones de asentamiento, particularmente en la segunda mitad del siglo xx y aceleradas por el notable e importante incremento de población producto de la creciente actividad industrial en la zona, requerían de áreas de expansión que, ante la escasez, no dejaba muchas ni mejores opciones (Aliste, Almendras \& Contreras, 2012). 
figura 1 | Plano de la Bahía de Concepción de A. Coste, 1790

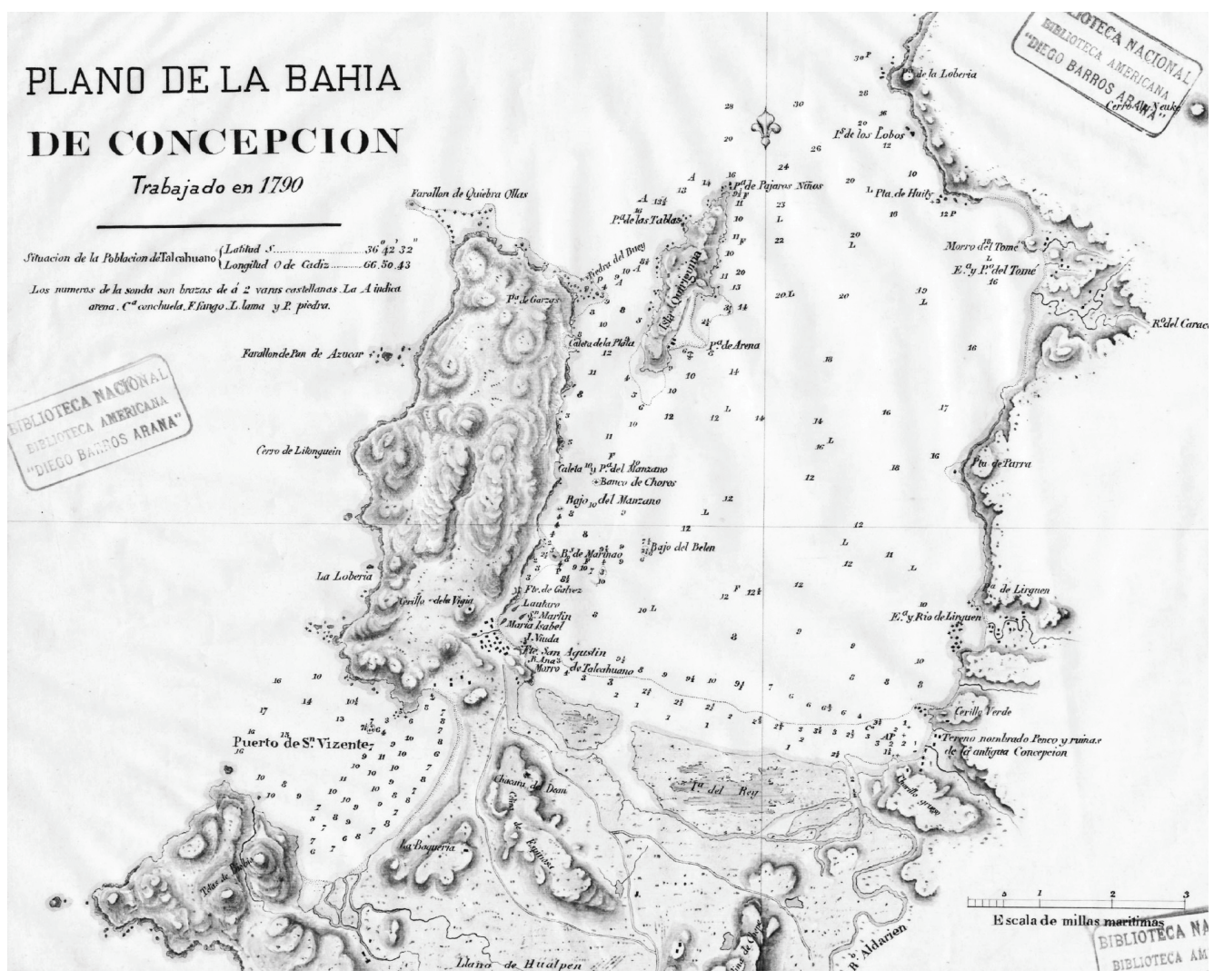

FUENTE HTTP://WWW.MEMORIACHILENA.CL/TEMAS/DOCUMENTO_DETALLE2.ASP?ID=MCOOOOO5I

Lo cierto es que los eventos sísmicos de 1939 y 1960 dejaron profundas huellas en el modo de pensar la ciudad y la acción pública. Debido a los efectos del terremoto de 1939, por ejemplo, se crearon nuevas instituciones, como la Corporación de Reconstrucción y Auxilio, dependiente del Ministerio de Hacienda, y también la Corporación de Fomento de la Producción $(\mathrm{CORFO})^{3}$, con importantes alcances a nivel nacional (Aliste \& Pérez, 2013). Algunos de los efectos físicos consecuencia del terremoto de 1939 -más allá de la desaparición de una parte importante de las construcciones de la ciudad (Pacheco, 1997, habla de la demolición de cerca del 60 por ciento de los edificios de Concepción) - fueron las diversas modificaciones urbanas realizadas a partir de las necesidades de reconstrucción. Entre ellas, el ensanche de calles, la creación de la diagonal que conecta los Tribunales con la Universidad de Concepción, la prolongación del parque Ecuador y dotación de algunos espacios públicos adicionales, que fueron incorporados en el Plan Regulador de 1940, elaborado por la Corporación de Reconstrucción y Auxilio, sin mayores transformaciones del tejido urbano. Se sumaron obras relevantes, como el Hospital Clínico

3 Ley 6.634 del 29 de abril de 1939, que crea las Corporaciones de Reconstrucción y Auxilio (actual Oficina Nacional de Emergencia, onemi) y la Corporación de Fomento de la Producción (CORFO). 
Regional, nuevos edificios públicos, remodelaciones, etcétera, cuya materialización tomó en algunos casos hasta casi treinta años (Pacheco, 1997).

El terremoto de 1960, por su parte, tuvo como consecuencia la instalación de gran cantidad de viviendas de emergencia en la zona de Hualpén ${ }^{4}$, que luego dieron origen a 4.000 unidades habitacionales realizadas por la Corporación de la Vivienda (CORVI ), en terrenos que le fueron expropiados a la familia Price (Vallette $\&$ Martínez, 2008). Muchas poblaciones nacieron en esta época; están, por una parte, aquellas creadas para acoger a los damnificados, como también las destinadas a dar solución al problema de vivienda que se inició con la masiva llegada de población a trabajar en las nuevas industrias creadas en la zona a partir de 1950 (Franck \& Pérez, 2009). Destacan, entre ellas: Recinto Estación Perales (1960), Población Armando Alarcón del Canto (1961-1962), Villa Acero (1962), Lan A y Lan B (1968-1974), René Schneider (1970-1972), Luis Emilio Recabarren (1971), Lan C (1970-1978), Los Bloques (1972), Villa Hualpén (1982), Aurora de Chile (1985), Peñuelas 1 y 2 (1989 y 1990), por señalar algunas que se aprecian en la Figura 2 (Hualpén, 2012).

\section{FIGURA 2 | Alrededores Club Hípico, 1962. Hualpén}

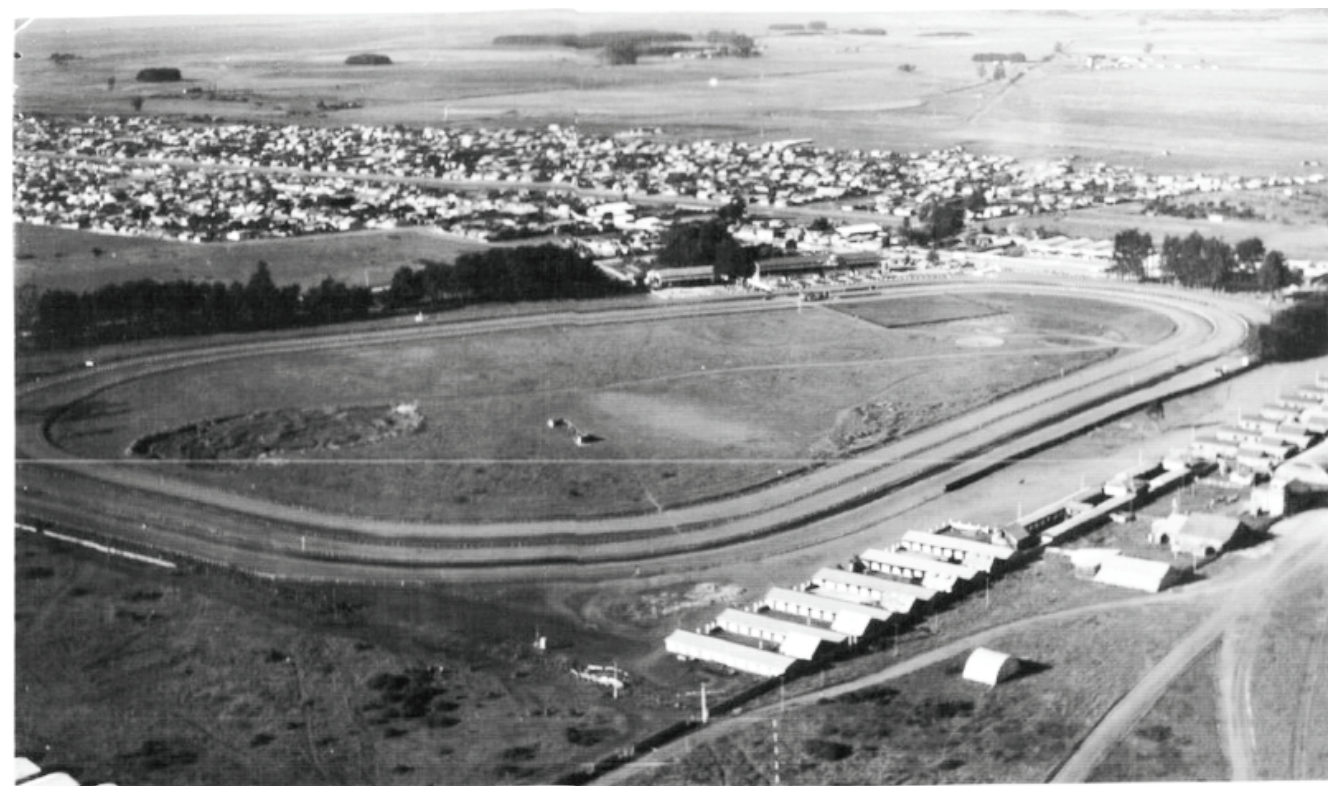

FUENTE SIBONA, I 962

Si de relación habitual con las aguas y los estremecimientos de la tierra se trata, la población Santa Clara, de Talcahuano, tiene una historia de más de cien años sobre el tema. Desde sus orígenes ${ }^{5}$, fuertemente golpeada por maremotos y por inundaciones, ha ido construyendo un particular proceso identitario relacionado con el

4 Hoy es una comuna más del AMc, creada el 15 de marzo de 2004 a partir de territorios administrativamente pertenecientes a la comuna de Talcahuano.

5 De acuerdo con Lagos (2010), se remontarían al ańo 1907 con la llegada de pescadores artesanales a la zona, quienes habrían creado allí un pequeño embarcadero (caleta) para la pesca artesanal, donde además era posible practicar la caza, debido a la abundancia de aves en la marisma de Rocuant. 
agua, en tanto ha sido la fuente de trabajo tradicional en esta área, sea por la pesca artesanal e industrial, o bien por el trabajo en los astilleros o en el mismo puerto. Diversos testimonios rescatados por Lagos (2010) aluden a la frecuencia de inundaciones, las que -de acuerdo con los habitantes entrevistados- se habrían agravado con la construcción de las industrias pesqueras durante los años ochenta, al ser edificadas sus instalaciones sobre rellenos que no permiten el adecuado drenaje de las aguas que antes tenían mayor superficie para desplazarse (Lagos, 2010, p. 80).

¿En qué se traduce el acto de habitar cuando las condiciones son adversas $\mathrm{u}$ hostiles? No es una respuesta sencilla ni única la que se busca. Por el contrario, se trata más bien de una pregunta que provoque e invite a insistir en el acto de observar con parsimonia y detenimiento el acto mismo de habitar en un territorio hostil; un territorio al que las huellas que el agua ha dejado por su frecuente visita en tierra, y la tierra por sus sacudidas reiteradas, le dan ese sello respecto del cual la sensibilidad no puede soslayarse como parte esencial en la construcción social del territorio.

\section{Ambientes en tensión, realidad social en construcción: el pantano se convierte en humedal, los "bichos" en biodiversidad}

Las formas de ocupación del espacio en la zona no han sido ni obvias ni carentes de esfuerzos relevantes para la ciudad. Aquellos atributos físico-naturales destacados como potencialidades para la generación de riquezas han sido, al mismo tiempo, los elementos que desde el punto de vista de la construcción de hábitat han representado condiciones de fragilidad ambiental (Smith \& Romero, 2009) o bien de dificultades prácticas para la urbanización (Pérez \& Salinas, 2009; Ilabaca, 1993; Mardones \& Vidal, 2001). La idea desarrollista plantea sin duda este tipo de desafíos. Al momento de concebir económicamente los pasos y medidas que harán parte del avance y el progreso social, se piensan las acciones posteriores que irán dando respuesta a las necesidades que coyunturalmente vayan surgiendo, como la de "ganar espacio a la naturaleza”, de gran frecuencia (Bernard, 1989; Coquery-Vidrovitch, Hemery \& Piel, 1988). Entre las primeras consecuencias de la industrialización de la zona, sin duda están los procesos de crecimiento demográfico (Aliste, Contreras \& Sandoval, 2012) que, consecuentemente, van instalando el tema de la demanda de suelo para viviendas de los trabajadores llegados a la zona (Fuentes \& Pérez, 2010), que aumentó fuertemente como consecuencia del terremoto de 1960 (Franck \& Pérez, 2009).

Los cambios en la tendencia demográfica en el marco de la construcción de la planta siderúrgica de Huachipato entre 1942 y 1950, año de su inauguración, han tenido importantes repercusiones territoriales, en tanto representan presiones sobre la necesidad de suelo urbano. Y es precisamente aquí donde surge el elemento más destacable desde una perspectiva en que se conjugan, por una parte, lo social, y por otra, lo ambiental: las presiones por el uso del suelo apuntaban innegablemente a aprovechar "los suelos inservibles de los pantanos" y a recuperarlos para anexarlos a la ciudad, idea que en determinados sectores sociales persiste hasta hoy.

El Plan Regulador Intercomunal de 1963, de hecho, propone una porción de las zonas pantanosas como "zonas residenciales mixtas", mientras otra como "zonas de expansión esparcimiento” (Pérez \& Fuentes, 2010). No es del todo descabellado 
que se pensara así en momentos donde el pantano, en tanto lugar, aparecía como el nicho natural de elementos negativos que solo oponen resistencia y dificultad al proceso civilizatorio. Tal como se refleja en la magistral obra de Lucien Febvre (1931), la "civilización", en tanto palabra e idea, sufre mutaciones esenciales durante el paso del tiempo y busca por lo mismo cumplir propósitos que son situados y contextualizados de manera diferente, dependiendo de las mentalidades que culturalmente le otorgan sentido a la palabra. En la Concepción de los ańos cincuenta, que se erige con hidalguía luego del devastador terremoto de 1939, y luego en la de los ańos sesenta, nuevamente devastada por un trágico y desalmado terremoto, que la vuelve a tumbar en apenas poco más de veinte años de distancia, ganar espacio a aquella naturaleza poco generosa parecía una idea plausible. Aun hoy es posible encontrar un sinnúmero de testimonios que se refieren a las "tierras inútiles", "inservibles" o "sin uso" que representan las zonas pantanosas. Basta mirar la clasificación de capacidades de uso de suelos utilizada por el antiguo Instituto de los Recursos Naturales (IREN) ${ }^{6}$, que clasifica estas tierras en categoría VII y VIII, que quiere decir "suelos sin valor agrícola, ganadero o forestal (...) en el que se incluyen dunas activas, pedregales, pantanos o suelos destruidos por la erosión” (Stolpe, 1997, p. 16).

Crecer urbanamente sobre tierras sin valor agrícola, ganadero o forestal, parece ser el ideal en el contexto de las ideas desarrollistas. Representa incluso un avance propio del buen uso de la razón y de los conocimientos acumulados por el saber científico y técnico de la época. Ganar espacio a los suelos inservibles es, qué duda cabe, un acto que refleja de buena forma la idea de progreso presente en el contexto desarrollista (Coquery-Vidrovitch et al., 1988). Es, por lo demás, la resultante en el avance de la modernidad como idea latente y viva en una sociedad que se reconstruye y enfrenta las nuevas ideas instaladas como discurso. La idea del desarrollo comienza a adquirir imagen en la medida en que materializa acciones de esta índole y en tanto logra dar paso desde la condición "salvaje" de un territorio a un progresivo proceso de urbanización; está siendo consecuente, desde tal punto de vista, al materializar la ciudad imaginada en el avance sobre los espacios desdeñados, como cumpliendo la epopeya propia del progreso. Los instrumentos de planificación lo van reflejando (en 1963, 1980 e incluso en 2003) y, de esta forma, la ciudad va adquiriendo la impronta del discurso responsable de tales avances. La adscripción a él permite ir dando respuesta a la creciente presión por soluciones habitacionales, proveniente tanto del sector industrial como de otras actividades que atraen población a la zona, y que comienzan a conformar y articular el nuevo paisaje de la geografía social de Concepción.

Por otra parte, se sostiene la existencia de un enorme desconocimiento de las características y atributos geográficos y ambientales de los terrenos que se comenzaban a utilizar para la expansión urbana. $\mathrm{Al}$ respecto, caben dudas sobre ese desconocimiento, teniendo en cuenta la sucesiva frecuencia de eventos catastróficos registrados a lo menos desde la fundación de la ciudad, su posterior traslado por las mismas razones en 1753 (Musset, 2010; Mazzei \& Pacheco, 1985), el testimonio de Darwin sobre lo sucedido en la bahía de Concepción en 1835 (registro empleado 
por el Servicio Hidrográfico y Oceanográfico de la Armada de Chile [sHOA] en enero de 2000 para elaborar la carta de riesgo de inundación por tsunami, según consta en su página web7) y los eventos de 1939, 1960 y 2010.

Desde el punto de vista estrictamente ambiental, sería injusto pedir para esos años conocimientos o antecedentes referidos a las características ecosistémicas en la zona. Durante la década de los sesenta en Chile, la noción de lo ambiental (como hoy lo entendemos) era absolutamente desconocida y extraña. Lo más vanguardista en este sentido sería escrito a inicios de los ańos setenta por Rafael Elizalde Mac-Clure desde el Ministerio de Agricultura, pensando en la conservación de los recursos naturales. No fue sino hasta la segunda mitad de los años ochenta cuando se comienza a tener una conciencia más acabada de las dificultades y problemas ambientales en la zona, a propósito de estudios realizados en el campo de la biología y la limnología en particular, y al importante impulso dado a las ciencias ambientales por la Universidad de Concepción con la creación del Centro de Ciencias Ambientales EULA-Chile, apoyado por universidades italianas.

Lo cierto es que a partir de los fuertes y notables avances de la actividad industrial desde los ańos cincuenta, que van consolidándose en el tiempo y que se coronan durante los ańos ochenta con el fortalecimiento de la industria pesquera, el desarrollo -registrado no solo en los aumentos del PIв regional o las mejoras en la infraestructura general de la ciudad-comienza a hacerse sentir en el aire, en el agua y en el suelo. El indeseable testimonio de la contaminación, como consecuencia directa del camino iniciado para alcanzar paulatinamente el tan anhelado desarrollo, comienza a perturbar y a incomodar este tránsito en la vida de los habitantes, especialmente en Talcahuano. La dimensión de lo sensible comienza a desempeñar un papel en la articulación de este territorio, que adquiere así una nueva característica: se trata ahora de un territorio contaminado y ambientalmente deteriorado.

Los problemas ambientales comienzan entonces a surgir poco a poco y a partir de dos frentes: por una parte, las innegables incomodidades y restricciones en el uso de las playas; el mal olor en el aire; el malestar propio de una cotidianidad que comienza a sentir el peso del desarrollo como externalidad negativa, producto de la contaminación provocada por las industrias de la zona. Pero hay otro frente menos evidente y que comienza a hacer sentir el peso y consecuencia de los costos de este progreso centrado en la industria y de lo que el crecimiento urbano trae consigo: es el frente generado por el acceso al conocimiento. Investigaciones científicas desarrolladas fundamentalmente por la Universidad de Concepción comienzan a alertar, a inicios de los ańos noventa, sobre una nueva noción: el impacto ambiental. Producto de ello y de los compromisos adquiridos en el contexto del proceso de regreso a la democracia luego de la dictadura militar, se crea hacia fines de 1990 el Programa de Recuperación Ambiental de Talcahuano, más conocido como PRAT. En el marco de dicho programa, se da inicio no solo a una serie de estudios orientados a establecer las magnitudes y alcances de los procesos de deterioro ambiental en la ciudad, sino también al diseño de un plan de acción que permita, en el mediano plazo, ir superando las dificultades existentes en este sentido (Valenzuela, 2002).

Véase http://www.shoa.cl/servicios/citsu/pdf/citsu_talcahuano.pdf 
Acciones de esta naturaleza, coordinadas luego por la Comisión Regional del Medio Ambiente creada en 1994 con ocasión de la promulgación de la Ley No 19.300 de Bases Generales del Medio Ambiente, fueron generando un interesante proceso de incremento de los conocimientos sobre las condiciones ambientales de la ciudad. Estudios no solo en el área de la contaminación ambiental, sino también en el campo de la ecología, los ecosistemas, los estudios territoriales, entre muchos otros, van permitiendo poco a poco pensar en una mirada integral y dejan en evidencia las relevantes complejidades de este territorio. La frecuente invitación a las miradas holísticas del tema ambiental tiende a coincidir en la necesidad de una concepción integral del territorio. Y con esta mirada, nuevos marcos teóricos y nuevas complejidades comienzan a emerger en esta escena, lo que, de acuerdo con Arnold (2003), da pie al mismo tiempo a la emergencia de nuevas amenazas para la sociedad.

Es aquí, con la emergencia de nuevos conocimientos, que surge un proceso relevante de nueva valoración del territorio. La transformación del territorio en el plano del conocimiento y los nuevos antecedentes que comienzan a permear paulatinamente las políticas y acciones públicas en el plano discursivo, comienzan a repercutir en la forma de mirar, apreciar y valorar el entorno; el territorio se transforma así tanto en su dimensión físico-natural, como en la manera en que la sociedad comienza a conocerlo y entenderlo. La ciudad imaginada cambia una vez más, para modificarse del mismo modo la experiencia de habitarla. Las transformaciones, por lo tanto, no son solo materiales, sino que también ocurren en el plano del imaginario que le va otorgando sentido a la ciudad.

Uno de los ejemplos más simbólicos y potentes de la tensión sociedad-naturaleza emerge como una consecuencia no solo de lo físicamente observable, sino también de lo socialmente representado (Arruda \& De Alba, 2007): en Concepción, el que siempre fue pantano o marisma, comienza paulatinamente a transformarse en humedal, pasando de estar plagado de bichos a ser una zona de rica biodiver$\operatorname{sidad}^{8}$. Esta dinámica es trascendental para comprender las mutaciones espaciales, en primer término, pero más aún para aproximarse a la dinámica de los territorios en su sentido más amplio; es decir, abarcando aquellos aspectos propios de las mutaciones que se pueden observar materialmente en los sistemas físico-naturales, pero también aquellas que emergen desde los sistemas sociales en tanto testimonio de las transformaciones de la sociedad y de sus formas de representar, valorar y registrar su entorno (Banchs, Agudo \& Astorga, 2007; Roncayolo, 2002; Arnold, 2003).

A partir de tal enfoque es que se propone la idea de que el territorio, así como tiene sus bases en los elementos tangibles y visibles, también las tiene en aquello que no necesariamente se ve, pero que sí se vive (Di Méo, 1999); esto es, el territorio comienza a transformarse y centra su dinámica no solo en las evidencias físicas y palpables, sino también en aquellas que son resultado de procesos socioculturales,

8 En la Memoria Explicativa de la Zonificación del Borde Costero, elaborada por el Gobierno Regional (GORE) del Biobío, se señala como fundamentación de la necesidad de contar con áreas de protección de la naturaleza lo siguiente: "La región tiene un área metropolitana altamente urbanizada e industrializada; esta percepción del espacio valoriza áreas como los santuarios de la naturaleza, las reservas nacionales y nuevas áreas sin protección, donde hay un alto valor por la biodiversidad presente, desembocadura de ríos, humedales, etc.” (GORE Bío Bío, 2006, p. 21). 
como la generación de nuevos conocimientos y nuevas valoraciones de ese mismo espacio con nuevos atributos que crean nuevos territorios.

Las huellas que deja el paso del tiempo en el espacio no solo se escriben con sus intervenciones físicas; también las formas de concebir, de percibir y de conocer van a generar transformaciones y marcas relevantes en el territorio. Los discursos siempre van dejando sus huellas en el territorio.

\section{¿Un desarrollo sin territorio?}

Uno de los aspectos clave del discurso del desarrollo es que sin importar dónde se haga, lo que se busca instalar es un modelo que homogeneice la forma de la vida moderna. Las nociones inspiradas en ese ideario propio de la modernidad, donde la igualdad ocupa una parte importante y donde la disociación entre tiempo y espacio es vital para la posibilidad de difusión de estas ideas (Giddens, 1991), terminan teniendo como consecuencia -entre otras- la desvinculación con el espacio donde los procesos se llevan a cabo.

Espacio y tiempo disociados implican un tiempo acorde con el discurso, pero un espacio que se ve como mero soporte para dar posibilidad o continuidad a la estructura discursiva del tiempo (Soja, 1989). Y por otra parte, el espacio como objeto de la planificación no siempre responde a la coherencia de ese discurso. Más aún si comparamos tal enfoque con las prácticas espaciales que podemos denominar como "el discurso fáctico del desarrollo". En este sentido y bajo esta premisa, algunas acciones interesantes son las relativas a la dimensión de la planificación del territorio a partir de los ańos sesenta en adelante. La búsqueda de coherencia entre las directrices de la planificación, las acciones concretas efectuadas (como las ocupaciones efectivas del suelo versus las sugerencias de los planes) y el papel o grado de vinculación de los actores con dichos procesos, construye una difusa conexión y relación entre el acto de habitar y la ocupación del espacio (Escobar, 2008).

En los diferentes planes de desarrollo elaborados entre 1960 y 2010, considerando aquellos de escala comunal (Planes de Desarrollo Comunal) y de alcance regional y nacional (Estrategias y Planes de Desarrollo Urbano y de Desarrollo Regional) la tendencia es similar: lo propuesto y lo hecho no coinciden al ser revisados en el tiempo (Díaz, 2010).

Por otra parte, en el plano discursivo sostenido por los propios actores sociales en el área de estudio, es interesante comprobar que ante un amplio espectro ideológico y político, la similitud entre los discursos en lo que se refiere a la idea de desarrollo es un dato relevante. Pese a las diferencias ideológicas, valóricas y sociales, hay un punto donde los discursos se encuentran al enfrentar, por ejemplo, el tema ambiental, y este es el imperativo de avanzar hacia un desarrollo sustentable (Aliste \& Rabi, 2012). Sin embargo, aunque los objetivos políticos y económicos son tan diferentes, ¿por qué aquí se encuentran? En este sentido, no resulta novedad subrayar que para identificar a los sectores de izquierdas, aún hoy en día se persiste en la denominación "sectores progresistas", claramente aludiendo a sus orígenes en el siglo XIX, cuando sostenían como idea fuerza la noción de progreso, la misma que luego es reemplazada por la de desarrollo (Coquery-Vidrovitch et al., 1988). 
Elemento fuertemente destacado en este anclaje conceptual es, sin duda, la noción de razón y la necesidad de su utilización para acoger un uso adecuado y "racional" del espacio, como de la mayor parte de las actividades humanas desarrolladas desde la segunda mitad del siglo XIX, y especialmente durante todo el siglo XX.

En referencia a lo planteado en el párrafo anterior, es interesante la utilización que se da a la dimensión racional en el uso del espacio. Al respecto, es necesario destacar que las miradas y conceptualizaciones sobre el espacio soportan aún hoy en día el innegable peso de los discursos desarrollistas. Un ejemplo de ello aparece en un reciente artículo publicado en 2010, como parte del trabajo compilatorio y analítico de Pérez e Hidalgo (2010). Allí, Rodríguez (2010) ${ }^{10}$, con una interesante mirada construida desde el urbanismo, propone leer el humedal de Rocuant-Andalién (o Carriel Sur) como un "vacío metropolitano nodal"11. Entre los argumentos analíticos, la idea central es la existencia allí de un vacío de urbanidad que se puede transformar en una oportunidad de proyecto, considerando las ventajas y potencialidades que este vacío metropolitano ofrece, por ejemplo, para su uso residencial.

Es interesante detenerse acá en la alusión a un espacio vacío. ¿Vacío en qué sentido? Sabemos - pues lo aporta incluso la misma autora- que se trata de un lugar donde existe un humedal valorizado en los últimos ańos como área natural, con valor ecosistémico, que representa una oportunidad para la ciudad en términos de servicios ambientales (Smith \& Romero, 2009). Se sabe, por lo demás, que es una zona de riesgo por tsunami, constatado tanto por el sHOA en 2000 en su carta de riesgo, como por el reciente evento del 27 de febrero de 2010 y en testimonios existentes en terreno.

¿En qué sentido se piensa esta noción de vacío? Es un vacío que se define por la falta de urbanidad (Rodríguez, 2010). Y esta urbanidad es en esencia uno de los pilares de lo que implica el proyecto desarrollista como estrategia civilizatoria. La presencia de lo urbano, sin embargo, configuraría también el lugar donde comparecen la vida y el modo de pensar urbano, más allá del tipo de paisaje allí presente (Lefebvre, 1970). En tal sentido, el lugar visto como "vacío" sería uno cuya urbanidad ya estaría presente en el modo de concebirlo como área de valor natural; sin

9 Se entiende la razón como "el uso público del pensamiento y el juicio, que recupera al sujeto como constructor de su propia razón, es decir, es el sujeto el que puede destruir las diversas figuras míticas y edificar un saber validado por acuerdos. El uso público de la razón se relaciona con la intersubjetividad y posibilidad del consenso con el fin de ejercer la libertad de decisión, que emancipará al hombre de sus tutelas tanto materiales como ideológicas” (Ramírez, 2000, p. 53).

10 No se trata aquí de querer rebatir o desacreditar lo desarrollado por la autora, sino, más bien, rescatar el artículo como un testimonio de una mentalidad presente hoy en día en una importante cantidad de obras, acciones y formas mediante las cuales tendemos a leer el paisaje y a entender el contexto urbano.

11 La propuesta de Rodríguez (2010) es entender los vacíos metropolitanos como "presencia del espacio vacío en la ciudad, como lugar con significado en la comprensión del espacio ausente de urbanidad. Como espacio potencial y transformador que puede ser apropiado por la ciudad, para la generación de nuevos escenarios que van acogiendo las diversas escalas urbanas" (p. 255). Agrega el autor, además, que entre los aspectos que más bien definen a los espacios vacíos, están la topografía y las condiciones ambientales; señala al respecto que se trata de "espacios de alto valor ecosistémico y de gran valor educativo y recreativo de contacto con la naturaleza, que en los últimos años se han visto revalorizados como espacio natural al mejoramiento de la calidad de vida urbana, en especial, para la actividad residencial" (p. 257). 
embargo, la insistencia en su incorporación a la trama urbana de la ciudad para no interrumpir la continuidad de esta es un buen reflejo de una mentalidad fuertemente anclada en un modo de vida marcado por una racionalidad desarrollista. Lo que importa acá es detenerse en la forma de mirar, en el modo de describir, en el acto mismo de pensar aquel entorno que es materia de análisis: el espacio que no admite una continuidad, o un continuum coherente con las formas geométricamente establecidas como normales de la ciudad, o bien que no logra ser parte de un tejido urbano continuo, merece ser considerado como un vacío (Figuras 3 y 4). Es decir, un espacio con ausencia de intervención humana sería parte de este vacío, aun cuando ya posee una valoración social que lo convertiría en un espacio urbano cuyo valor está en su condición de no uso. Es, al menos, el testimonio de habitantes que viven en las nuevas villas colindantes al humedal Rocuant (Beltrán, 2011).

¿Qué implica este tipo de diagnóstico descriptivo para el territorio que se construye y produce desde estos discursos? Implica suponer la existencia de un discurso del desarrollo que no posee una connotación espacial y en el cual la forma geométrica con que se piensa la ciudad no se encuentra necesariamente con la forma o estructura geográfica propia de la conformación de los territorios. Se trata de un discurso que persiste en la idea de no incorporar las condiciones del espacio natural como parte esencial del territorio, a menos que este esté "conteniendo los atributos propios de dicho discurso". Es decir, el espacio como soporte de dichos discursos.

FIGURA 3 | Concepciones del espacio

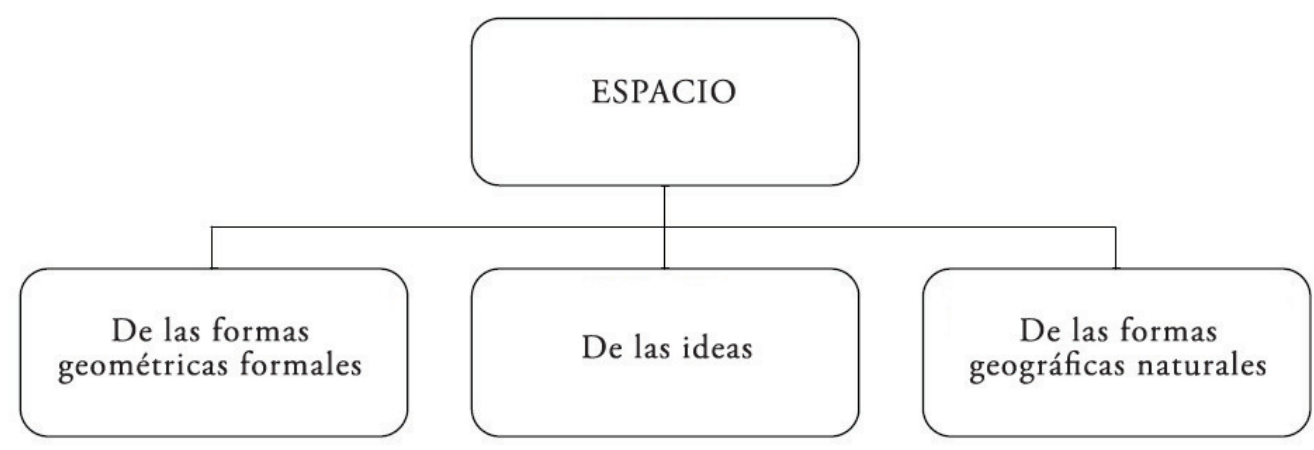

FUENTE ELABORACIÓN PROPIA BASADA EN DI MÉO, I998

Es esta forma de entender el espacio la que ha guiado la acción pública en el AMC (y en Chile en general). La idea de la planificación urbana y sus estrategias, contenidas en los respectivos planes, llevan a pensar en ese deseo de ciudad ausente, aquella ciudad imaginada contenida en la formalidad del discurso planificador, en cada línea que define los planes, planos y cartografías orientadores de una ciudad mejor; una ciudad que se hace mejor en la medida en que da cabida a la noción de desarrollo como discurso anclado en una racionalidad marcada a su vez por la regularidad geométrica que hace la formalidad, que busca alejarse de aquello naturalmente presente y que representaría la esencia de aquella barbarie que la civilización requiere vencer. 
Aquí no se trata de desechar ni negar la importancia, ni mucho menos las virtudes, de lo que ha significado el discurso del desarrollo, sino sencillamente hacer una lectura crítica anclada en su correlato espacial. Mirar las repercusiones de este discurso en el territorio, se sostiene aquí, colabora con dar otro foco a procesos en pleno curso y que ponen de manifiesto algunas dificultades prácticas de la planificación urbana, como por ejemplo, la de no tener la posibilidad de ser vista en su dimensión subjetiva y en su condición imaginaria; esto es, en la manera en que la ciudad va configurándose en el dominio de quienes la viven: por una parte, quienes la piensan, la planifican o tienen la responsabilidad de gestionarla, mientras que por otra, quienes la habitan y la viven en su dimensión cotidiana.

FIGURA 4 | Representación del "vacío metropolitano nodal” en el sector del humedal Rocuant - Andalién (o Carriel Sur)

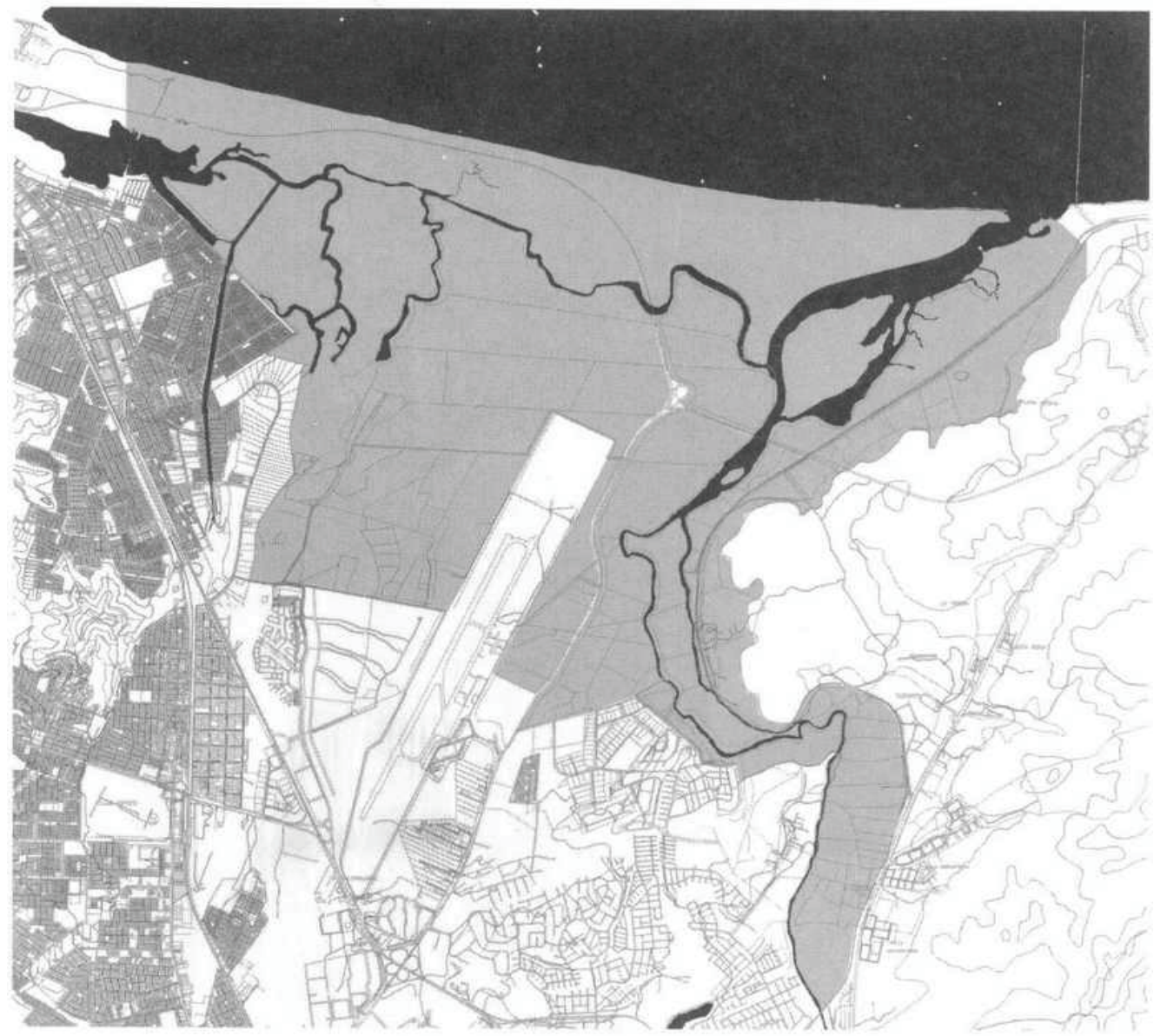

FUENTE RODRÍGUEZ, 2OIO, EN PÉREZ E HIDALGO, 20 IO

En consecuencia, la noción de un desarrollo sin territorio encuentra entre sus argumentos esta idea de ver el espacio como mero soporte de las acciones y elementos contenidos en el discurso del desarrollo, sin una proximidad realmente integrada de las diferentes aproximaciones al espacio que permiten definir y constituir territorios (Di Méo, 1998). 


\title{
Ciudad imaginaria, ciudad vivida: a modo de conclusión
}

\begin{abstract}
¿Cómo definir una ciudad imaginaria? En primer lugar, como una ciudad que no figura en ninguna carta, en ningún atlas del tiempo presente, pero en donde, sin embargo, se puede pasear, contemplar su esplendor arquitectónico, discutir con sus habitantes (...). En función de las proporciones entre el sueño y la realidad, entre lo racional y lo poético, podemos distinguir las ciudades reinventadas, las ciudades soñadas, las ciudades ideales. Una categorización más alquimica que cientifica, que no tiene otro objetivo que facilitar al lector la exploración de aquellos territorios en los márgenes de los mundos conocidos y desconocidos.

(J. N. Mouret, Le goût de villes imaginaires)
\end{abstract}

¿Por qué referirse a Concepción como una ciudad imaginaria? ¿Por qué vincular la acción pública en función de los discursos del desarrollo? La idea general de la ciudad, en su conjunto, no puede considerarse como perteneciente al dominio exclusivo de las formas, pues no está constituida solo de su trama material, y las huellas de los mecanismos que contribuyen a la creación del espacio urbano son también parte esencial de ella (Roncayolo, 2002). De esta forma, lo visible y lo invisible, lo objetivo y lo subjetivo, lo tangible y lo intangible resultan imprescindibles en este intento por mirar el territorio desde una óptica amplia, que se plantee como desafío acoger y aceptar la complejidad que contiene en sí mismo como concepto. Es decir, para examinar los contornos de aquella ciudad que se mueve en experiencias y deseos disímiles, la noción de imaginario permite acceder a estas diferentes dimensiones dadas, entre otras, por una planificación que la define en el papel y que dista muchas veces de lo que se hace en su dimensión material en el terreno.

El derrotero de la ciudad de Concepción en poco más de medio siglo, mirado en perspectiva y entrecruzado con los elementos que la han ido configurando en su plano discursivo o como resultado de determinadas prácticas, ha quedado registrado tanto en los instrumentos diseñados para planificar el desarrollo, como en las huellas territoriales que han definido en gran parte su geografía social actual, en tanto que las formas de representar la ciudad hacen ver ciertos conflictos por una falta de coherencia entre discursos y prácticas. La acción pública -en una primera mirada y desde las consecuencias que ha tenido y que se han visto a través del tiempo- puede ser juzgada y criticada en virtud de aspectos que varían y cambian en el seno de la sociedad, que también cambia. Sin embargo, aquí queremos sostener más bien otro aspecto: una ciudad imaginaria es aquella que se sueña, se diseña, se planifica y se piensa a la luz de ciertos discursos; aquí, ese discurso ha sido el discurso del desarrollo. Sin embargo, y como se ha visto, muchas veces este discurso puede desembocar en la negación, o bien en el desafío que implica mirar a través de dichos discursos, que impiden ver o valorar el sentido y peso de aquellos elementos que quedan fuera de la argumentación discursiva. Ello, que no necesariamente está mal o bien, es más bien una señal que debemos esforzarnos por entender. Mirar o aproximarse desde la perspectiva de los imaginarios es una posibilidad. Por ello, mirar cómo se articulan discursos y prácticas es interesante. 
Lo que queda a la vista en este cruce es la disociación entre una ciudad contenida en sus instrumentos, en los documentos que la definen, la describen, la imaginan y la planifican, respecto de aquella que se vive por sus habitantes y que se hace materialmente tangible en sus diferentes formas de ocupación. Las consecuencias del desarrollo, por una parte, fueron sus aportes e incrementos demográficos, crecimiento del PIB, diversificación de actividades, etcétera, como también notables condiciones de deterioro ambiental, particularmente en las décadas de los ochenta y noventa. Pero, por otra parte, también en esos años surgen nuevos conocimientos que crean condiciones de revaloración del entorno, estableciendo un nuevo contexto territorial que suma elementos de complejidad en la dinámica del territorio, en tanto las representaciones construidas constituyen mutaciones ya no solo en su dimensión físico-natural, sino también en su plano conceptual y cultural.

Si bien lo anterior impregna los nuevos discursos con nociones como la sustentabilidad ambiental y la revaloración de la naturaleza, también es fuerte la persistencia de las ideas desarrollistas clásicas, especialmente en las propuestas y formas de pensar las intervenciones espaciales a futuro. En este sentido, se sostienen algunas ideas interpretativas respecto de la relevancia y peso que tienen los discursos del desarrollo en su nivel de incidencia territorial, propuestas en las que se destacan los aspectos siguientes:

- Los discursos, en tanto se concretan en los instrumentos que contienen las ideas para darle un sentido y forma a la ciudad (como representación imaginaria), hacen visible una ciudad deseada, sońada, imaginada. Se desprende de los instrumentos y testimonios una forma de ver y aproximarse a la ciudad y su territorio, que se abre a una expresión de deseo en unos casos, de malestar en otros, de añoranza.

- Las prácticas espaciales, por su parte, leídas como "el discurso fáctico del desarrollo", son las huellas que impregnan el espacio del contenido temporal de los discursos del desarrollo; esto es, que le dan soporte a dichos discursos. Sin embargo, ante la persistencia en la disociación entre tiempo y espacio, pareciera hacerse patente la falta de concordancia entre lo que se declara o dice, respecto de lo que se hace o materializa. Los discursos del desarrollo contienen y dan relevancia al papel del tiempo, en tanto el rol del espacio se reduce a ser el soporte de estos discursos en lo fáctico (Soja, 1989). La consecuencia de ello, en el caso de Concepción, es una ciudad contenida en sus instrumentos, y otra contenida en la experiencia y acciones materiales como productoras de territorios y de una particular geografía social.

- La morfología de la ciudad es parcialmente resultado de determinadas prácticas discursivas no coincidentes. Por una parte, rige un discurso fuertemente guiado por ideas de corte hegemónico y ancladas en el uso racional del espacio, que recientemente incluye las ideas de valor natural, servicios ambientales y en general de desarrollo sustentable. Por otra parte, en cambio, las diferentes prácticas espaciales muestran la persistencia -aún hoy en día- de ideas desarrollistas clásicas de los ańos sesenta, que proponen usar residencialmente suelos en zonas de riesgo, de valor natural u otros atributos restrictivos, en virtud de mantener una coherencia de continuidad urbana, es decir, planteada con criterios geométricos o morfológicos más que integrados. 
- Lo anterior nos lleva a otros planteamientos respecto de los argumentos que se suelen esgrimir para insistir en una idea de desarrollo urbano. A partir del análisis ensayístico efectuado, lo que se busca es cuestionar la idea de un desarrollo urbano visto como tendencia natural que conlleva necesariamente mejoras. Lo que se sostiene es la idea de mejoras que tendrán la temporalidad propia de la historia, pues lo que podemos constatar a través de una geohistoria reciente de la ciudad, es su condición dinámica, que no depende solo de las transformaciones físico-materiales, sino también de aquellas que suceden en el plano intelectual y que van permeando la sociedad a través de su presencia como acción pública.

Con todo, hablar de los discursos del desarrollo reflejados en el territorio ofrece esta posibilidad de ver emerger una geografía diferente, compleja y -por qué no decirlo- también confusa, donde queda de manifiesto el papel y peso de lo social en su proceso de conformación. Las ideas o datos que científicamente colaboran en definir criterios o recomendaciones para una mejor gestión del territorio, no parecen ser suficientes en escenarios con la complejidad propia de la sociedad actual. Mirar lo imaginario también puede colaborar en esta enorme tarea, si se logra entender no como una mirada paralela, sino más bien como una observación complementaria que pone de manifiesto la dimensión de representación de aquella realidad procurada por quienes tenemos el desafío y propósito, además de la pretensión, de trabajar con la realidad. Después de todo, ¿qué es la realidad, sino esa dimensión de contexto que es concordada socialmente; y este acuerdo, a su vez, un complejo resultado de representaciones de diferente orden en donde lo imaginario es una dimensión más?

\section{Referencias bibliográficas}

Aliste, E. \& Pérez, S. (2013). La reconstrucción del Gran Concepción: territorio y catástrofe como permanencia histórica. Revista de Geografia Norte Grande, (54), 199-218. http:// dx.doi.org/10.4067/S0718-34022013000100011

Aliste, E., Almendras, A. \& Contreras, M. (2012a). La dinámica del territorio en la conurbación Concepción - Talcahuano: Huellas urbanas para una interpretación de las transformaciones ambientales durante la segunda mitad del siglo xx. Revista de Geografía Norte Grande, (52), 5-18. http://dx.doi.org/10.4067/S0718-34022012000200001

Aliste, E., Contreras, M. \& Sandoval, V. (2012b). Industrialización, desarrollo y ciudad: transformaciones sociodemográficas y espaciales en la geografía social del Gran Concepción. Revista INVI, 27(75), 21-71. Recuperado de http://revistainvi.uchile.cl/ index.php/INVI/article/view/635

Aliste, E. \& Rabi, V. (2012). Concebir lo socioambiental: representación y representatividad de los discursos sobre el desarrollo. Revista Polis, 11(32), 307-327. http://dx.doi. org/10.4067/S0718-65682012000200015

Arnold, M. (2003). Autoproducción de la amenaza ambiental en la sociedad contemporánea. Revista MAD, (9), 1-31. Recuperado de http://www.facso.uchile.cl/publicaciones/ $\mathrm{mad} / 09 /$ paper01.pdf 
Arruda, A. \& De Alba, M. (2007). Espacios imaginarios y representaciones sociales. Barcelona: Anthropos.

Banchs, R., Agudo, A. \& Astorga., L. (2007). Imaginarios, representaciones y memoria social. En A. Arruda, \& M. de Alba, Espacios imaginarios y representaciones sociales (pp. 4795). Barcelona: Anthropos.

Beltrán, M. (2011). Transformaciones espaciales y valoración social del Humedal RocuantAndalién: una dinámica socioecológica de medio siglo. Informe de práctica profesional (realizada en el marco del Proyecto FONDECYT 1090248). Santiago: Facultad de Arquitectura y Urbanismo, Universidad de Chile (inédita).

Bernard, P. (1989). Histoire du développement économique. Paris: Éditions Marketing - École Polythécnique.

Braudel, F. (1997). Les ambitions de l'histoire. Paris: Éditions de Fallois.

Chesneau, I. \& Roncayolo, M. (2011). L'abécédaire de Marcel Roncayolo. Entretiens. Gollion (Suiza): Infolio Éditions.

Coquery-Vidrovitch, C., Hemery, D. \& Piel, J. (1988). Pour une histoire du développement. États, sociétés, développement. Paris: L'Harmattan.

Di Méo, G. (1998). Géographie sociale et territoires. Paris: Nathan Université.

Di Méo, G. (1999). Géographies tranquilles du quotidien. Une analyse de la contribution des sciences sociales et de la géographie à l'étude des pratiques spatiales. Cabiers de géographie du Québec, 43(118), 75-93.

Di Méo, G. \& Buléon, P. (2005). L'espace social. Lecture géographique des sociétés. Paris: Armand Colin.

Díaz, A. (2010). Transformaciones territoriales: los imaginarios del desarrollo territorial en Concepción-Talcahuano (1960-2010). Tesis para optar al grado de Magíster en Análisis Sistémico Aplicado a la Sociedad (elaborada en el marco del Proyecto fONDECyt 1090248), Facultad de Ciencias Sociales, Universidad de Chile, Santiago (inédita).

Elizalde Mac-Clure, R. (1970). La sobrevivencia de Chile. La conservación de sus recursos naturales renovables. Santiago: El Escudo, Impresores / Editores Ltda.

Escobar, A. (2008). Territories of difference: place, movements, life, redes. Durham, Nc: Duke University Press.

Febvre, L. (1931). Civilisation, le mot et l'idée. En L. Febvre, Civilisation. Evolution d'un mot et d'un group d'idées. (pp. 1-55). Paris: La Renaissance du Livre.

Franck, S. \& Pérez, L. (2009). Más que una suma de casas. La unidad vecinal Villa San Pedro de Coronel. Revista INVI, 24(67), 127-152. Recuperado de http://www.revistainvi. uchile.cl/index.php/INVI/article/view/468

Frémont, A. (1995). Les profondeurs des paysages géographiques. En A. Roger, La théorie du paysage en France (1974-1994) (pp. 21-41). Seyssel (Francia): Champ Vallon.

Fuentes, P. \& Pérez, L. (2010). Orígenes del Concepción metropolitano: conjuntos residenciales aportados por la industria y el Estado. En L. Pérez, \& R. Hidalgo, Concepción Metropolitano. Evolución y desafios (pp. 83-121). Concepción: Universidad de Concepción / Serie GEO-Libros (PUC).

Giddens, A. (1991). The consequences of modernity. St. Redwood City, CA: Stanford University Press, 1991. 
Gobierno Regional del Bío Bío (gore Bío Bío), Comisión Regional de Uso del Borde Costero. (2006). Zonificación Borde Costero, Región del Bio Bio. Memora Explicativa. Concepción: Autor. Recuperado de http://www.yumpu.com/es/document/view/7586971/zonificacionborde-costero-region-del-bio-bio

Hernández, H. (1983). El Gran Concepción: desarrollo histórico y estructura urbana. Primera parte. Génesis y fundación. De las fundaciones militares a la conurbación industrial. Informaciones Geográficas, (30), 47-70.

Hualpén, I. Municipalidad de. (2012, enero 30). http://www.hualpenciudad.cl/. Recuperado de http://www.hualpenciudad.cl/index.php?option=com_content\&view=article\&id= 19\&Itemid $=27$

Ilabaca, P. (1993). El riesgo de anegamiento en la llanura litoral de Concepción-Talcahuano. Proposición metodológica. Revista Geográfica de Chile Terra Australis, (38), 65-72.

Ilabaca, P. (1995). Condiciones naturales y crecimiento urbano: caso comuna de Talcahuano. Revista Geográfica de Chile Terra Australis, (40), 7-29.

Lagos, P. (2010). Transformaciones y apropiaciones socioculturales del territorio desde mediados del siglo XX a la actualidad: el caso de la Población Santa Clara, Talcahuano. Memoria para optar al título de antropólogo (en el marco del Proyecto fondecyt 1090248), Facultad de Ciencias Sociales, Universidad de Concepción.

Lefebvre, H. (1970). Du rural à l'urbain. Paris: Anthropos.

Mardones, M. \& Vidal, C. (2001). La zonificación y evaluación de los riesgos naturales de tipo geomorfológico: un instrumento para la planificación urbana en la ciudad deConcepción. EURE, 27(81), 97-122. http://dx.doi.org/10.4067/S0250-71612001008100006

Mazzei, L. \& Pacheco, A. (1985). Historia del traslado de la ciudad de Concepción. Concepción: Ediciones de la Universidad de Concepción.

Mouret, J.-N. (2011). Le goût des villes imaginaires. Paris: Mercure de France.

Muñoz, F. (2011). Instrumentos de planificación territorial del Área Metropolitana de Concepción (AMC) y su relación con los modelos de desarrollo (1960-2010). Memoria para optar al título profesional de Geógrafo (realizada en el marco del Proyecto Fondecyt 1090248), Facultadde Arquitectura y Urbanismo, Universidad de Chile, Santiago (inédita).

Musset, A. (2010). Vulnerabilidad social, justicia espacial y resiliencia. Concepción, Chile, entre dos terremotos (1751-1835). En A. Musset, Ciudad, sociedad, justicia: un enfoque espacial y cultural (pp. 31-64). Mar del Plata: Eudem, Universidad Nacional de Mar del Plata.

Pacheco, A. (1997). Historia de Concepción. Siglo XX. Concepción: Cuadernos del Bio-Bío (Universidad de Concepción / I. Municipalidad de Concepción).

Pérez, L. \& Fuentes, P. (2010). El Plan Regulador Intercomunal de 1963 (PRIC). Inicios de la planificación metropolitana. En L. Pérez, \& R. Hidalgo, Concepción Metropolitano. Evolución y desafios (pp. 45-58). Concepción: Universidad de Concepción / Serie GEO-Libros (pUc).

Pérez, L. \& Hidalgo, R. (2010). Concepción Metropolitano. Evolución y desafios. Concepción: Universidad de Concepción / Serie GEO-Libros (PUC). 
Pérez, L. \& Salinas, E. (2009). Fragmentos de ciudad. Formas de crecimiento del Concepción Metropolitano. En R. Hidalgo, C. De Mattos \& F. Arenas (Eds.), Chile: del país urbano al país metropolitano (pp. 269-300). Santiago: Pontificia Universidad Católica de Chile. Serie GEO-Libros, Serie EURE-Libros.

Piglia, R. (2003). La ciudad ausente. Barcelona: Anagrama.

Ramírez, R. (2000). Razón y racionalidad. Una dialéctica de la modernidad. Convergencia, 7(21), 49-89. Recuperado de http://www.redalyc.org/articulo.oa?id=10502102

Rodríguez, M. (2010). Vacíos, espacios agrarios, intersticios metropolitanos del AMC: Oportunidades para un proyecto territorial. En L. Pérez, \& R. Hidalgo, Concepción Metropolitano. Evolución y desafios (pp. 253-268). Concepción: Universidad de Concepción / Serie GEO-Libros (PUC).

Rojas, C., Muniz, I., \& García, M. (2009). Estructura urbana y policentrismo en el Área Metropolitana de Concepción. EURE, 35(105), 47-70. http://dx.doi.org/10.4067/ S0250-71612009000200003

Roncayolo, M. (2002). Lecture des villes. Formes et temps. Marseille: Éditions Parenthèses.

Schlögel, K. (2007). En el espacio leemos el tiempo. Sobre historia de la civilización y geopolítica. Madrid: Siruela.

Sibona, S. (1962). Influencia de los factores potenciales de la industria, agricultura y las reservas forestales en la expansión urbana de Concepción. Seminario de Planeación Urbana. Santiago: Facultad de Arquitectura y Urbanismo, Universidad de Chile.

Smith, P. \& Romero, H. (2009). Efectos del crecimiento urbano del Área Metropolitana de Concepción sobre los humedales de Rocuant-Andalien, Los Batros y Lenga. Revista de Geografia Norte Grande, (43), 81-93. http://dx.doi.org/10.4067/S071834022009000200005

Soja, E. (1989). Postmodern geographies. The reassertion of space in critical social theory. London: Verso.

Stolpe, N. (1997). Clasificaciones interpretativas. (Apuntes Departamento de Suelos). Chillán: Facultad de Agronomía, Universidad de Concepción.

Valenzuela, J. (2002). Estudio de caso GWP: Recuperación Ambiental Integral de la Comuna de Talcahuano. Global Water Partnership (GWP), Integrated Water Resources Management.

Vallette, A. \& Martínez, C. (2008). Identidad urbana de la comuna de Hualpén y algunos de sus principales elementos urbano poblacionales. Urbano, 11(18), 92-96. Recuperado de http://www.redalyc.org/articulo.oa?id=19811648014 